\title{
Hubungan Antara Keterlibatan Mengikuti Kegiatan Ekstrakurikuler Dengan \\ Psychological Well-Being Mahasiswa Emerging Adulthood \\ Universitas X di Surabaya
}

\author{
Natasha Gandhi ${ }^{1}$ Sri Wahyuningsih ${ }^{2}$ dan Nurlita Indah Karunia ${ }^{3}$ \\ Email: eugenia.gandhi@gmail.com ${ }^{1}$ \\ Program Studi Psikologi, Fakultas Psikologi, Universitas Surabaya ${ }^{1,2,3}$
}

\begin{abstract}
Abstrak
Psychological Well-Being adalah suatu kemampuan individu merealisasikan serta mengoptimalkan dirinya dengan cara menerima diri seutuhnya, memilki kemandirian dan tidak terpengaruh dari tekanan luar, mampu mengontrol lingkungan di sekitarnya, mampu membangun relasi sosial, memiliki tujuan hidup yang jelas, serta dapat merealisasikan potensi dirinya secara kontinyu. Salah satu faktor yang memengaruhi psychological well-being mahasiswa ialah keterlibatan mengikuti ekstrakurikuler. Penelitian ini bertujuan untuk menguji hubungan antara keterlibatan mengikuti ekstrakurikuler dengan pscyhological well-being. Pengambil sampel dilakukan dengan menggunakan teknik purposive sampling. Subjek penelitian ini adalah mahasiswa Universitas Surabaya sebanyak 192 mahasiswa (131 perempuan dan 61 laki-laki). Teknik analisis yang digunakan ialah uji hipotesis dengan Pearson. Berdasarkan hasil uji korelasi Pearson menunjukkan adanya korelasi siginifikan positif antara keterlibatan mengikuti ekstrakurikuler dengan psychlogical wellbeing $(\mathrm{r}=0.154, \mathrm{p}=0.033)$. Sumbangan efektif yang diberikan keterlibatan mengikuti ekstrakurikuler dengan psychological well-being ialah sebesar $2 \%$. Keterlibatan mengikuti ekstrakurikuler berkorelasi dengan aspek psychological well-being yakni aspek personal growth $(\mathrm{r}=0.177, \mathrm{p}=0.014)$ dan aspek positive realtion with others $(\mathrm{r}=0.0215, \mathrm{p}=0.003)$.
\end{abstract}

Kata kunci: emerging adulthood, keterlibatan mengikuti ekstrakurikuler, psychological well-being.

\begin{abstract}
Psychological well-being is an individual's ability to realize and optimize of himself by accepting himself, having independence and not depending on outside pressure, being able to control the surrounding environment, being able to establish positive relationships with others, have goals in life, and can realize his potential continuously. One of the factors that affect students' psychological well-being is the involvement of extracurricular activities. This study aimed to examine the relationship between involvement in extracurricular activities and psychological well-being. Sampling method is using purposive sampling technique. The subjects of this study were 192 students of Universitas Surabaya (131 women and 61 men). The analysis technique applies hypothesis test with Pearson technique. Based on the result of Pearson correlation test, that shows a positive significant correlation between involvement extracurricular activities with psychological well-being $(r=0.154, p=0,033)$. The effective contribution given by involvement extracurricular activities with psychological well-being is $2 \%$. The involvement of extracurricular activities is correlated with the psychological well-being aspect is personal growth aspect $(r=0.177, \mathrm{p}=0.014)$ and positive relation with others aspect $(\mathrm{r}=0.0215, \mathrm{p}=0.003)$.
\end{abstract}

Keywords: Emerging Adulthood, Involvement Of Extracurricular, Psychological Wel-Being

\section{PENDAHULUAN}

Psychological well-being ialah

sebuah kemampuan untuk merealisasikan

dirinya serta mengoptimalkan

kehidupannya (Ryff, 1989). Keyes,

Shmotkin, \& Ryff, (2002) menyatakan psychological well-being ialah suatu

proses yang dijalani oleh individu agar dapat mengembangkan potensi yang dimiliki sehingga mampu menghadapi tantangan kehidupan yang ada. Bradburn

(dalam Ryff \& Keyes,

1995) 
menambahkan bahwa kebahagiaan adalah hasil dari tingginya tingkat kesejahteraan psikologis. Bradburn juga menjelaskan bahwa kebahagian merupakan tujuan tertinggi dan merupakan sebuah keinginan yang ingin dicapai oleh banyak orang.

Menurut Ryff (1989) ciri-ciri individu yang mempunyai psychological well-being tinggi ialah mampu menerima kelebihan dan kekurangan pada dirinya terutama terhadap kehidupannya di masa lampau, mampu untuk bertumbuh dan mengembangkan diri, adanya keyakian bahwa hidup memiliki makna dan tujuan, mampu membangun dan menjaga relasi sosial, mampu untuk menyesuaikan lingkungan sesuainya kemampuannya, serta memiliki kemampuan untuk menentukan dan mengambil keputusan sendiri. Molina-Garcia, Castillo, \& Queralt (dalam Ludban \& Gitimu, 2015) menyatakan bahwa psychological wellbeing bermanfaat bagi orang-orang dewasa untuk menjalani kehidupan yang sehat, dan menjadi aspek penting dalam tahun-tahun perkuliahan. Tahun-tahun perkuliahan yang dilalui individu di perguruan tinggi, terutama di awal perkuliahan, seringkali merupakan salah satu periode paling menegangkan karena merupakan suatu transisi dari masa remaja ke dewasa. Mahasiswa yang memiliki kesejahteraan psikologis yang kurang baik, cenderung terlibat dalam aktivitas negatif seperti penggunaan alkohol, pasif, kurang tidur atau terlalu banyak tidur (Cao, dalam Ludban \& Gitimu, 2015).

Mahasiswa adalah individu pada masa emerging adulthood. Emerging adulthood merupakan suatu periode dari masa akhir remaja hingga melalui usia dua puluhan yang difokuskan pada individu yang berada pada batas usia 18-25 tahun. Bagi kebanyakan orang, pada usia tersebut merupakan suatu kesempatan untuk mengeksplorasi berbagai kemungkinan dalam cinta, pekerjaan dan cara pandang terhadap dunia (Erikson; Rindfuss, dalam Arnett, 2000). Eksplorasi dalam hal percintaan mulai mengarah kehubungan yang lebih intim dan serius. Begitu juga, eksplorasi dalam pekerjaan yang lebih berfokus pada persiapan untuk peran kerja dewasa. Tidak hanya terbatas pada persiapan untuk peran dewasa, eksplorasi pada emerging adulthood ini juga untuk kepentingan diri sendiri dan merupakan bagian dari memperoleh berbagai pengalaman sebelum mengambil tanggung jawab dan batasan-batasan sebagai orang dewasa (Arnett, 2000). Mahasiswa memasuki rentang usia yang memiliki karakteristik senang dalam mengekplorasi hal-hal yang baru dalam dunia perkuliahan, seperti mengikuti beberapa kegiatan di luar perkuliahan 
seperti ekstrakurikuler baik itu latihan rutin maupun organisasi. Hal ini bertujuan sebagai bekal untuk masa dewasa nantinya.

Ekstrakurikuler ialah kegiatan akademik atau non-akademik yang dilakukan dibawah naungan sekolah namun terjadi di luar jam kelas dan bukan bagian dari kurikulum. Selain itu kegiatan ekstrakurikuler tidak termasuk dalam sks dan merupakan pilihan sendiri dari siswa (Bartkus, Nemelka, Nemelka dan Gardner, 2012). Dalam penelitian ini, ekstrakurikuler yang dimaksud ialah kegiatan yang diselenggarakan diluar jam perkuliahan oleh fakultas maupun universitas seperti organisasi kemahasiswaan, latihan rutin, dan kepanitiaan. Mahasiswa dibebaskan memilih kegiatan ektrakurikuler berdasarkan minatnya

Berdasarkan wawancara singkat kepada tiga mahasiswa yaitu $\mathrm{N}, \mathrm{M}$ dan $\mathrm{T}$ memberikan gambaran manfaat yang didapatkan ketika mengikuti kegiatan ekstrakurikuler. Mahasiswi N, M dan T sama-sama memiliki tujuan dalam memiliki kegiatan ekstrakurikuler seperti menambah relasi, pengalaman, mengisi waktu luang dan mengasah bakat yang ada. Manfaat yang didapatkan oleh mahasiswi $\mathrm{N}$ dan $\mathrm{M}$ sejalan dengan tujuan mereka yaitu menambah relasi. Selain menambah relasi, mahasiswi $\mathrm{N}$ dan $\mathrm{M}$ juga mendapatkan manfaat yang lain yaitu pengalaman untuk memanfaatkan lingkungannya disekitarnya. Seperti contohnya mahasiswi $\mathrm{N}$ mengatur hubungan yang akan dijalin antar satu pihak dengan pihak yang lain. Apabila hubungan berhasil terjalin dengan baik maka akan menguntungkan mahasiswi $\mathrm{N}$ apabila ada keperluan tersebut.

Mahasiswa N, M dan T sama-sama memiliki karakteristik terbuka terhadap pengalaman baru, mau menghadapi tantangan yang baru serta mau berkembang. Terlihat juga pada saat mahasiswi $\mathrm{T}$ yang awalnya memiliki kemampuan awal menjadi cheerleader, kemudian mau mencoba bidang olah raga yang akhirnya membuat mahasiswi $\mathrm{T}$ menjadi menyadari bahwa ia ada bakat di bidang lainnya. Hal ini juga didukung oleh karakteristik $\mathrm{T}$ yang positif terhadap dirinya sendiri.

Berdasarkan hasil survei awal berbagai macam manfaat didapatkan mahasiswa yang mengikuti kegiatan ekstrakurikuler. Manfaat-manfaat yang didapatkan menggambarkan beberapa aspek psychological well-being seperti tujuan hidup, relasi sosial, mengatur lingkungan, pengembangan diri, serta penerimaan diri. Aspek tujuan dapat dilihat dari adanya tujuan akhir yang ingin 
diperoleh dan adanya makna dalam kegiatan yang dilakukan. Aspek hubungan positif dengan orang terlihat ketika mahasiswi tersebut mampu menjalin relasi dengan teman-teman yang ada dilingkup kegiatan ekstrakurikuler. Aspek penguasaan lingkungan terlihat ketika individu tersebut mampu mengatur lingkungannya berdasarkan pada kebutuhannya. Aspek pengembangan diri terlihat ketika mahasiswi tersebut dapat melihat dirinya sebagai orang yang mau mengembangkan diri, mencoba hal-hal baru dan dapat melihat potensi yang ada pada dirinya. Aspek menerima diri terlihat ketika cara seseorang memandang dirinya secara positif dan mau membuka diri terhadap kelebihan dan kekurangan pada dirinya (Ryff, 1989).

Adanya aspek-aspek yang muncul dari manfaat yang didapatkan ketika mengikuti ekstrakurikuler menunjukkan adanya hubungan antara ekstrakurikuler dengan psychological well-being mahasiswa. Pada penelitian Rocha, Mcleod, \& Bohnert (2017) dan Guzman (2013) menunjukkan bahwa remaja yang aktif terlibat dalam kegiatan yang teorganisir dapat mempengaruhi wellbeing remaja terutama pada aspek selfworth dan locus of control. Oosterhoof, Kaplow, Wray-Lake dan Gallagher (2017) menambahkan durasi remaja dalam kegiatan turut memengaruhi well-being remaja tersebut. Kegiatan yang teorganizir ialah salah satu bentuk dari kegiatan ekstrakurikuler. Hal ini sejalan dengan wawancara awal, yaitu adanya manfaat seperti menambah relasi, menentukan tujuan yang ingin dicapai, memanfaatkan lingkungan yang ada, mau belajar, dan memandang diri secara positif. Manfaat yang didapatkan oleh mahasiswa tersebut menunjukkan dimensi-dimensi yang ada di psychological well-being.

Berdasarkan penjelasan di paragraph sebelumnya, terdapat kemungkinan keikutsertaan mahasiswa dalam ekstrakurikuler memiliki hubungan dengan psychological well-being. Hal inilah yang menjadi dasar peneliti untuk meneliti lebih lanjut terkait pengaruh keterlibatan mahasiswa dalam kegiatan ekstrakurikuler terhadap psychological well-being mereka.

\section{METODE PENELITIAN}

Populasi pada peneltian ini adalah mahasiswa universitas $X$ di Surabaya dan sampel penelitian ini sebanyak 192 orang. Kriteria subjek yang harus dipenuhi yakni pertama, memiliki jenis kelamin perempuan dan laki-laki. Kedua, termasuk dalam tahap emerging adulthood yakni berusia 18-25 tahun. Ketiga, berstatus mahasiswa aktif di Universitas $X$. 
Keempat, mengikuti kegiatan ekstrakurikuler di tingkat fakultas atau universitas.

Teknik pengambilan sampel dilakukan dengan metode purposive sampling, yakni pemilihan subjek sesuai dengan ketentuan yang dibuat oleh peneliti. Ketentuan tersebut dibuat sesuai dengan tujuan penelitian. Pada proses pengambilan data, skala pengukuran yang disebarkan mencapai 205 skala pengukuran, namun hanya 192 skala yang diisi lengkap dan dapat dianalisis.

Alat ukur yang digunakan yakni skala psychological well-being, dan skala keterlibatan mengikuti kegiatan ekstrakurikuler. Skala psychological wellbeing yang digunakan adalah hasi dari modifikasi alat ukur Ryff (1989) dan telah dikembangkan oleh Sihombing (2016). Kemudian skala keterlibatan mengikuti kegiatan ekstrakurikuler dibuat sendiri oleh peneliti yang mencangkup aspek intensitas dan konsistensi.

Skala psychological well-being memiliki 30 pernyataan (positif dan negatif). Terdapat enam macam jawaban yang terdiri dari Sangat Tidak Setuju sampai Sangat Setuju. Skala keterlibatan mengikuti kegiatan ekstrakurikuler memiliki 3 pernyataan (positif). Terdapat dua macam pilihan, pilihan pertama yakni selalu, sering, kadang-kadang, jarang dan tidak pernah. Pilihan kedua yakni $>20$ jam, 10-19 jam, 5-9 jam, 1-4 jam, dan $<1$ jam.

Azwar (2014) menyatakan bahwa validitas suatu alat tes tergolong baik jika alat tersebut dapat mengukur berdasarkan tujuan alat ukur tersebut. Validitas yang digunakan adalah validitas isi yang diuji dengan cara melihat kesesuaian isi alat ukur melalui analisis yang dilakukan oleh orang-orang yang ahli pada bidang tersebut atau expert judgment (Azwar, 2014). Azwar (2014) juga menyatakan suatu instrument tergolong reliabel jika instrument tersebut dapat menunjukkan hasil yang cenderung sama apabila dilakukan pengukuran kembali pada subjek yang sama. Syarat alat ukur akan tergolong realiabel apabila memiliki nilai chronbach alpha $(\alpha)$ minimal $\geq 0,7$.

Semua proses analisis data dilakukan dengan SPSS versi 22. Uji asumsi terdiri dari dua macam yakni uji normalitas dan uji linearitas. Setelah uji asumsi selesai dilakukan, dilanjutkan dengan uji hipotesis menggunakan metode uji korelasi pearson.

\section{HASIL PENELITIAN}

\section{Karakteristik Subjek}

Jumlah partisipan pada penelitian ini yakni 192 orang dengan rincian yakni 61 orang laki-laki dan 131 orang 
perempuan. Subjek berusia 17-23 tahun dengan mayoritas berada pada berusia 20 tahun yaitu 72 orang. Subjek penelitian berasal dari tujuh fakultas di Universitas $\mathrm{X}$ dan mayoritas subjek berasal dari fakultas psikologi yaitu sebanyak 44 orang atau sebesar $22.9 \%$.

\section{Uji Asumsi}

Uji normalitas digunakan untuk menguji disribusi penyebaran data, sebagai ketentuan sebelum melanjutkan ke uji statistik lainnya. Katz (2011) menjelaskan bahwa uji normalitas tidak diperlukan apabila sample yang digunakan dalam penelitan berjumlah lebih dari 100 subjek, sehingga diasumsikan bahwa data yang digunakan normal. Uji normalitas tidak dilakukan dikarenakan subjek dalam penelitian ini jumlahnya di atas 100 subjek yaitu 192 subjek.

Uji linieritas ialah suatu uji untuk melihat hubungan antara variabel tergantung dan bebas dengan melihat garis (sejajar atau tidak) yang ada (Sugiyono, 2014). Kedua variabel yang memiliki $\mathrm{p}<0.05$ sehingga dapat ditarik kesimpulan bahwa varibel tersebut berhubungan secara signifikan linier. Hasil uji lineritas terhadap dua variabel memiliki nilai signifikansi $0,033 \quad(p<0,05)$. Hal ini menunjukkan bahwa kegiatan mengikuti ekstrakurikuler dengan psychological well-being berhubungan secara linier.

\section{Uji Hipotesis}

Berdasarkan dari uji korelasi variabel kegiatan mengikuti ekstrakurikuler dan psychological wellbeing didapatkan hasil nilai signifikansi $0.033(\mathrm{p}<0.05)$. Hal ini menjelaskan bahwa keterlibatan dalam kegiatan ekstrakurikuler berhubungan secara signifikan dengan psychological wellbeing.

\section{PEMBAHASAN DAN KESIMPULAN}

Tabel 1 Uji korelasi antara aspek psychological well-being dan ekstrakurikuler

\begin{tabular}{|c|c|c|c|}
\hline Variabel & $\mathbf{r}$ & $\mathbf{P}$ & Status \\
\hline $\begin{array}{l}\text { Ekstrakurikuler } \\
\text { dan Personal } \\
\text { Growth }\end{array}$ & 0.177 & 0.014 & Ada Hubungan \\
\hline $\begin{array}{l}\text { Ekstrakurikuler } \\
\text { dan Positive } \\
\text { Relation with } \\
\text { Others }\end{array}$ & 0.215 & 0.003 & Ada Hubungan \\
\hline $\begin{array}{l}\text { Ekstrakurikuler } \\
\text { dan Autonomy }\end{array}$ & 0.012 & 0.870 & $\begin{array}{l}\text { Tidak Ada } \\
\text { Hubungan }\end{array}$ \\
\hline $\begin{array}{l}\text { Ekstrakurikuler } \\
\text { dan } \\
\text { Environtmental } \\
\text { Mastery }\end{array}$ & 0.049 & 0.500 & $\begin{array}{l}\text { Tidak Ada } \\
\text { Hubungan }\end{array}$ \\
\hline $\begin{array}{l}\text { Ekstrakurikuler } \\
\text { dan Purpose in } \\
\text { Life }\end{array}$ & 0.087 & 0.231 & $\begin{array}{l}\text { Tidak Ada } \\
\text { Hubungan }\end{array}$ \\
\hline $\begin{array}{l}\text { Ekstrakurikuler } \\
\text { dan Self } \\
\text { Acceptance }\end{array}$ & 0.077 & 0.287 & $\begin{array}{l}\text { Tidak Ada } \\
\text { Hubungan }\end{array}$ \\
\hline
\end{tabular}

Tabel 2 Hasil uji korelasi antar aspek psychological well-being dan aspek ekstrakuriler

\begin{tabular}{lccc}
\multicolumn{1}{c}{ Variabel } & r & P & Status \\
\hline $\begin{array}{l}\text { Personal Growth } \\
\text { dan Intensitas }\end{array}$ & 0.194 & 0.007 & $\begin{array}{c}\text { Ada } \\
\text { Hubungan }\end{array}$ \\
\hline $\begin{array}{l}\text { Personal Growth } \\
\text { dan Konsistensi }\end{array}$ & 0.110 & 0.130 & $\begin{array}{l}\text { Tidak Ada } \\
\text { Hubungan }\end{array}$ \\
\hline $\begin{array}{l}\text { Positive Relation } \\
\text { with Others dan } \\
\text { Intensitas }\end{array}$ & 0.203 & 0.005 & $\begin{array}{c}\text { Ada } \\
\text { Hubungan }\end{array}$ \\
$\begin{array}{l}\text { Positive Relation } \\
\text { with Others dan } \\
\text { Konsistensi }\end{array}$ & 0.117 & 0.107 & $\begin{array}{l}\text { Tidak Ada } \\
\text { Hubungan }\end{array}$ \\
\hline
\end{tabular}


Dari penelitan yang telah dilakuan diketahui bahwa mahasiswa Universitas X memiliki tingkat keterlibatan mengikuti ekstrakurikuler yang tinggi. Mayoritas dari partisipan penelitian ini berada dalam tingkat aspek intensitas sebanyak 82 mahasiswa $(42,7 \%)$ serta pada aspek konsistensi sebanyak 185 mahasiswa (96,4\%). Individu yang berpartisipasi dalam penelitian ini berada di usia 17-23 yang berada pada fase emerging adulthood. Arnett (2000) menjelaskan emerging adulthood ialah suatu periode dari pada akhir remaja hingga yang difokuskan pada rentang usia 18-25 tahun. Tingginya keikutsertaan pada ekstrakurikuler merupakan suatu bentuk dalam mengeksplorasi untuk mendapatkan berbagai pengalaman yang berguna pada saat mengambil peran dewasa. Salah satu bentuk eksplorasi yang dilakukan ketika diperkuliahan ialah ekstrakurikuler. Sebanyak 61 mahasiswa (31,8\%) mengikuti dua macam kegiatan dalam satu semester. Hal ini menandakan suatu bentuk eksplorasi untuk mendapatkan berbagai macam pengalaman untuk pengambilan peran pada dewasa nanti.

Pada tahap emerging adulthood, individu banyak mengeksplorasi berbagai kemungkinan dalam hal pekerjaan, cinta dan cara pandang terhadap dunia guna menyiapkan peran dewasa (Erikson;
Rindfuss, dalam Arnett, 2000). Berdasarkan hasil angket terbuka mengenai permasalahan yang ditemui, mayoritas mahasiswa memilih pembagian waktu antara perkuliahan dan ekstrakurikuler $\quad(71,35 \%) \quad$ serta kesalahpahaman antar anggota $(53,13 \%)$. Hal ini dapat menggambarkan tantangantantangan yang akan dihadapi ketika individu tersebut melakukan eksplorasi. Tantangan-tantangan tersebut tentunya diselesaikan oleh individu secara berbedabeda. Pada cara mengatasi permasalahan, sebanyak 128 mahasiswa $(66,7 \%)$ mengatasi permasalahan sendiri. Cara penyelesaian masalah ini dapat menggambarkan bagaimana cara individu mengambil sebuah keputusan serta menyelesaikan konflik yang ada tanpa bantuan dari orang lain. Pengalamanpengalaman yang didapatkan ketika menyelesaikan konflik dapat menjadi bekal individu pada masa dewasa.

Mayoritas partisipan penelitian mengikuti dua macam kegiatan dalam satu semester yakni sebesar 61 mahasiswa $(31,8 \%)$. Luasnya keterlibatan dalam ekstrakurikuler dapat memberi kesempatan bagi individu untuk merasakan mengatur berbagai aktivitas yang diikuti. Olahraga, organisasi, seni, penalaran dan panitia lepas memberikan kesempatan yang berbeda dalam 
mengembangkan kompetensi fisik, intelektual, sosial, emosional dan kesempatan dalam membentuk hubungan yang mendukung dengan berbagai orang dewasa dan rekan kerja (Hansen, Larson, \& Dworkin, 2003). Selain itu dengan mengikuti berbagai jenis ekstrakurikuler dapat digunakan sebagai lingkungan belajar dengan pengalaman sosialisasi yang berbeda (Larson \& Varma, 1999).

Hasil penelitian ini menunjukkan bahwa mayoritas mahasiswa Universitas $\mathrm{X}$ yang mengikuti ekstrakurikuler yakni $123(64,1 \%)$ mahasiswa mempunyai psychological well-being tinggi. Ciri-ciri orang yang mempunyai psychological well-being tinggi ialah mampu menerima kelebihan dan kelemahan diri sendiri, mempunyai relasi yang hangat dengan orang lain, mampu untuk bersikap mandiri dan yakin akan diri sendiri, menguasai lingkungan, mempunyai tujuan dan mampu melihat makna kehidupan, serta mengalami pertumbuhan kepribadian (Ryff, 1989). Tingginya tingkat psychological well-being seseorang ditunjukkan oleh aspek-aspeknya yang akan dibahas dibawah ini.

Aspek self acceptance menggambarkan rasa penerimaan akan kelebihan dan kelemahan yang ada pada diri (Ryff, 1989). Hasil penelitian menunjukkan sebanyak $92 \quad(47,9 \%)$ mahasiswa memiliki self-acceptance yang tergolong tinggi. Hal ini menandakan bahwa mahasiswa Universitas $\mathrm{X}$ mampu bersikap secara positif dalam memandang dirinya, menerima kelebihan dan kekurangan yang ada serta menerima kehidupan dimasa lampau yang tergolong tinggi.

Aspek positive relation with others menggambarkan kemampuan seseorang untuk menjalin relasi persahabatan dan hubungan cinta yang mendalam (Ryff, 1989). Berdasarkan hasil penelitian, didapatkan bahwa sebanyak 108 (56,3\%) mahasiswa memiliki aspek positive relation with others yang tergolong tinggi. Hal ini menandakan bahwa mayoritas mahasiswa Universitas $\mathrm{X}$ memiliki kemampuan untuk menjalin relasi yang hangat, membangun kepercayaan dengan orang lain, memunculkan rasa kepedulian terkait kondisi orang lain, adanya rasa empati, memberikan perasaan sayang, serta adanya hubungan timbal balik secara positif dengan orang lain.

Aspek pupose in life menggambarkan keyakinan individu tentang tujuan, niat serta perasan searah yang semuanya memiliki pengaruh pada perasaan kebermaknaan akan hidup (Ryff, 1989). Mayoritas mahasiswa Universitas $\mathrm{X}$ yakni $87(45,3 \%)$ mahasiswa memiliki purpose in life yang tergolong tinggi. Hal 
ini menandakan bahwa mayoritas mahasiswa Universitas $\mathrm{X}$ tergolong tinggi dalam menentukan tujuan dalam hidupnya, yang digambarkan dengan merasakan adanya makna yang ada di masa sekarang maupun dimasa lampau, memegang kepercayaan yang menjadi tujuan hidup, serta memiliki tujuan-tujuan dalam hidupnya.

Aspek personal growth menggambarkan kemampuan individu untuk berusaha menumbuhan dan mengembangkan potensi yang dimiliki agar mendukungnya menjadi pribadi yang utuh. Sebanyak 115 (59,9\%) mahasiswa memiliki personal growth yang tergolong tinggi. Hal ini menandakan bahwa mayoritas mahasiswa Universitas $\mathrm{X}$ merasa mampu mengembangkan diri, terbuka terhadap pengalaman baru, mampu melihat dirinya bertumbuh dan berkembang, melihat potensi yang belum terlihat, mampu menyadari peningkatan pada dirinya serta adanya perubahan perilaku menjadi lebih baik.

Aspek autonomy menggambarkan kemampuan individu dalam menganalisa dirinya secara objektif dan memutuskan sesuatu tanpa melibatkan atau terpengaruh orang lain. Mayoritas Universitas X yaitu $89(46,4 \%)$ mahasiswa memiliki autonomy tergolong cukup. Berdasarkan hasil dari angket terbuka mengenai cara mengatasi masalah yang ada, mayoritas subjek mampu untuk menyelesaikan permasalahan yang ditemui secara mandiri tanpa melibatkan pihak eksternal. Hal ini menandakan bahwa subjek mempu menyelesaikan serta membuat keputusan sendiri tanpa melibatkan orang lain.

Aspek environmental mastery menggambarkan kemampuan indivdu dalam melihat celah serta membangun lingkungan agar mendukungnya untuk mencapai tujuannya dan memenuhi kebutuhannya. Mayoritas mahasiswa Universitas $\mathrm{X}$ yakni $114 \quad(59,4 \%)$ mahasiswa memiliki enviromental mastery yang tergolong cukup. Hal ini menunjukkan bahwa mayoritas mahasiswa Universitas $\mathrm{X}$ memiliki kemampuan yang tergolong cukup untuk menguasai dan kapasitas untuk mengontrol lingkungan, cukup efektif dalam memanfaatkan peluang yang ada di sekitarnya dan mampu memilah hal-hal sekiranya mendukung untuk memenuhi kebutuhannya.

Menurut penelitian Ryff (1989), aspek yang paling tinggi di emerging adulthood ialah aspek personal growth. Pada penelitian ini terdapat empat aspek yang tergolong tinggi yakni self acceptance, personal growth, positive relation with others, dan purpose in life. Tingginya keempat aspek tersebut 
dikarenakan terdapat beberapa faktor yang mempengaruhi seperti status sosial, pendidikan, kepribadian (Ryan dan Deci, 2001; Marmot, 1998; Schummutte dan Ryff, 1997) sehingga diduga pada tahap emerging adulthood bukan hanya personal growth-nya saja yang tinggi, begitu juga dengan aspek-aspek lainnya.

$$
\text { Berdasarkan uji hipotesis }
$$
didapatkan hasil yakni adanya hubungan signifikan positif antara keterlibatan mengikuti kegiatan ekstrakurikuler dengan psychological well-being mahasiswa emerging adulthood Universitas X. Hasil ini diperoleh dari hasil uji hipotesis ini dengan perolehan nilai signifikansi yaitu $\mathrm{p}=0,033(\mathrm{p}<$ $0.05)$ serta perolehan nilai korelasi yaitu $r$ $=0,154$. Selain itu, Keterlibatan mengikuti kegiatan ekstrakurikuler memberikan sumbangan efektif sebesar 2\% pada psychological well-being.

Berdasarkan hasil dari tabulasi silang (tabel 2) dapat diketahui bahwa aspek intensitas berasosiasi dengan psychological well-being. Hasil ini menggambarkan, semakin individu aktif mengikuti kegiatan ekstrakurikuler maka semakin tinggi psychological well-being seseorang. Serta aspek intensitas dalam keterlibatan mengikuti ekstrakurikuler juga berpengaruh secara signifikan pada tingkat psychological well-being.
Kemudian pada uji tabulasi silang (tabel 1) didapatkan hasil bahwa subjek yang mempunyai psychological well-being tinggi memiliki tingkat intensitas yang tergolong tinggi.

Psychological well-being adalah kemampuan individu untuk merealisasikan diri dan mengoptimalkan kehidupannya. Tinggi rendanya psychological well-being yang dimiliki mahasiswa memiliki pengaruh terhadap tingkat kebahagiaan yang dimiliki. Apabila kesejahteraan psikologis mahasiswa cenderung rendah, dapat menimbulkan dampak seperti penggunaan alkohol, pasif, kurang tidur dan terlalu banyak tidur (Cao, dalam Ludban \& Gitimu, 2015). Terdapat beberapa fakor yang mempengaruhi psychological wellbeing yakni usia, jenis kelamin, status sosial, pernikahan, pendidikan, kepribadian dan support dari keluarga dan teman. Dukungan dari teman dapat didapatkan seseorang ketika mengikuti ekstrakurikuler. Gilman, Meyers \& Perez (2004), menemukakan bahwa terdapat beberapa manfaat mengikuti ekstrakurikuler yakni mendapatkan dukungan dari jaringan sosial, interaksi dengan orang yang berkompeten di bidangnya, serta kesempatan untuk berkembang. 
Hasil penelitian Gilman, Meyers \& Perez (2004) juga didukung oleh beberapa penelitian sebelumnya seperti pada penelitian Guzman, Mcleod dan Bohnert (2017) menjelaskan bahwa semakin seorang remaja terlibat aktif mengikuti ekstrakurikuler makan akan meningkatkan well-being remaja tersebut. Kemudian Busseri, Krasnor, Willoughby, dan Chalmers (2006), menyatakan bahwa tingginya intensitas mengikuti ekstarkurikuler dapat mempengaruhi tingginya tingkat well-being siswa. Intensitas merupakan salah satu aspek dari keterlibatan mengikuti ekstrakurikuler. Selanjutnya pada penelitian Oosterhoff, Kaplow, Lake, dan Gallagher (2017), menyatakan bahwa durasi mengikuti kegiatan ekstrakurikuler berkorelasi positif dengan well-being bagi siswa. Durasi juga merupakan salah satu dari aspek ekstrakurikuler. Bohnert (2010) menambahkan bahwa aspek durasi sama dengan aspek konsistensi dalam mengikti ekstrakurikuler yang artinya sama-sama mengukur lamanya individu mengikuti ekstarkurikuler. Penelitian-penelitian tersebut menunjukkan bahwa keikutsertaan ekstrakurikuler baik pada siswa maupun mahasiswa berkontribusi terhadap psychological well-being.

Hubungan positif antara keterlibatan mengikuti ekstrakurikuler dan psychological well-being pada tabel 1, juga dapat dijelaskan dari manfaat yang diperoleh mahasiswa ketika mengikuti ekstrakurikuler yang berpengaruh pada psychological well-being-nya. Berdasarkan angket terbuka didapatkan hasil bahwa mahasiswa yang mengikuti ekstakurikuler merasakan manfaat diantaranya menambah relasi $(87,5 \%)$, mengasah kemampuan yang dimiliki $(87,5 \%)$ serta mendapatkan kesempatan untuk mengembangkan diri $(69,27 \%)$. Manfaat tersebut dianggap sebagai aspekaspek yang mempengaruhi psychological well-being serta dibuktikan pada uji analisa lanjutan yang bertujuan untuk melihat hubungan keterlibatan mengikuti ekstrakurikuler dengan aspek-aspek psychological well-being (tabel 1). Berdasarkan analisa lanjutan tersebut dijelaskan bahwa keterlibatan mengikuti ekstrakurikuler berkorelasi terhadap aspek psychological well-being yaitu aspek personal growth dengan nilai signifikansi $0.014(\mathrm{p}<0,05)$ dan $\mathrm{r}=0.177$ dan aspek positive relation with others dengan nilai signifikansi $0.003(\mathrm{p}<0,05)$ dan $\mathrm{r}=$ 0.215 , namun tidak berkorelasi pada aspek autonomy, environment mastery, purpose in life, serta self-acceptance.

Tingginya tingkat keterlibatan dalam mengikuti ekstrakurikuler menandakan bahwa mahasiswa memiliki 
tingkat intensitas serta konsistensi yang tergolong tinggi. Semakin sering dan konsisten mahasiswa dalam mengikuti ekstrakurikuler, maka semakin mahasiswa itu merasa memiliki kemampuan dalam mengembangkan potensinya serta mampu memiliki hubungan persahabatan dan cinta yang dalam.

Menurut Ryff (1989), kemampuan individu dalam mengembangkan potensinya untuk tumbuh dan berkembang sebagai pribadi yang utuh disebut personal growth. Sebesar 115 mahasiswa $(59,9 \%)$ yang mengikuti ekstrakurikuler memiliki personal growth yang tergolong tinggi. Ciri-ciri individu yang memiliki personal growth tinggi ialah individu merasa dapat mengembangkan diri secara berkelanjutan, mau mencoba hal-hal baru, mampu melihat potensi didalam diri, mampu melihat peningkatan pada dirinya serta berubah menjadi lebih baik (Ryff, 1989). Hal ini dibuktikan pada angket terbuka diketahui bahwa dengan mengikuti ekstrakurikuler mahasiswa merasa mendapatkan manfaat yaitu mengasah kemampuan yang dimiliki $(87,5 \%)$ serta mendapatkan kesempatan untuk mengembangkan diri $(69,27 \%)$.

Menurut Ryff (1989), kemampuan individu dalam menjalin relasi persahabatan yang mendalam dan menjalani hubungan cinta yang lebih baik disebut positive relation with others. Hasil dari penelitian didapatkan hasil bahwa sebanyak 108 mahasiswa (56,3\%) memiliki aspek positive relations with others yang tergolong tinggi. Menurut Ryff (1989), individu mampu menjalin relasi secara positif dengan orang lain mempunyai ciri-ciri, yaitu: mempunyai relasi yang hangat, merasa puas dengan kualitas relasi yang dimilikinya, mampu membangun rasa percaya dalam berelasi, memiliki kepedulian terkait kondisi orang lain, mampu menunjukkan empati dan kasih sayang, serta terjalin hubungan timbal balik dalam relasi yang dibangun. Hal ini dibuktikan pada angket terbuka diketahui bahwa dengan mengikuti ekstrakurikuler mahasiswa merasa mendapatkan manfaat yaitu menambah relasi $(87,5 \%)$.

Pada keterlibatan mengikuti ekstrakurikuler terdapat dua aspek yakni aspek intensitas dan konsistensi. Berdasarkan uji analisa lanjutan yang bertujuan melihat hubungan antara aspek keterlibatan mengikuti ekstrakurikuler dengan aspek psychological well-being (tabel 2) diketahui bahwa yang memiliki hubungan ialah aspek intensitas. Terlihat pada tabel 2, bahwa intensitas memiliki korelasi aspek personal growth $(\mathrm{p}=$ 0.007; $\mathrm{p}<0,05 ; \mathrm{r}=0.194)$ dan positive relation with others $(\mathrm{p}=0.005 ; \mathrm{p}<0,05 ; \mathrm{r}$ 
$=0.203)$. Hasil tersebut menjelaskan semakin sering individu mengikuti ekstrakurikuler, maka ia akan mampu untuk mengembangkan diri serta berelasi dan memiliki hubungan positive dengan orang lain. Selain itu, didukung oleh penelitan Guzman-Rocha, McLeod, dan Bohnert (2017) bahwa aspek intensitas lebih berasosiasi dengan beberapa aspek well-being dibandingkan dengan aspek konsistensi.

\section{PENUTUP}

\section{Kesimpulan}

Berdasarkan pembahasan yang telah dijabarkan di atas, dapat ditarik kesimpulan bahwa keterlibatan mengikuti ekstrakurikuler memiliki hubungan yang signifikan dengan psychological wellbeing mahasiswa Universitas $\mathrm{X}$. Kemudian, keterlibatan mengikuti ekstrakurikuler memiliki sumbangan efektif sebepada psychological well-being sebesar 0,02. Sumbang efektif yang kecil menandakan bahwa terdapat beberapa faktor lainnya yang memiliki pengaruh lebih besar pada psychological well-being mahasiswa. Selain itu, keterlibatan mengikuti ekstrakurikuler hanya berkorelasi dengan dua aspek psychological well-being yakni aspek personal growth dan positive relation with others. Kemudian aspek keterlibatan mengikuti ekstrakurikuler yang berkorelasi dengan psychological wellbeing ialah aspek intensitas.

\section{Saran}

Saran bagi mahasiswa ialah mahasiswa dapat berperan aktif dalam kegiatan ekstrakurikuler pada tingkat Fakultas dan Universitas agar dapat memaksimalkan psychological well-being pada dirinya. Mahasiswa dapat lebih memanfaatkan semaksimal mungkin hal-hal yang didapatkan ketika mengikuti kegiatan ekstrakurikuler sehingga dapat mengoptimalkan psychological wellbeing.

Saran bagi penelitian selanjutnya yakni selain memperhitungkan aspek konsistensi dan intesnsitas dapat mempertimbangkan aspek breadth yang mengukur banyaknya ekstrakurikuler yang diikuti dalam satu waktu oleh individu. Selain itu, penelitian selanjutnya dapat mencari subjek yang rentang waktu keikutsertaan ekstrakurikuler lebih tinggi untuk lebih melihat konsistensi individu dalam mengikuti kegiatan ekstrakurikuler.

\section{DAFTAR PUSTAKA}

Arnett, J. J. 2000. Emerging Adulthood: A Theory of Development From the Late Teens Through the Twenties. American Psychologist, 55(5), 469-480.

Azwar, S. 2014. Reabilitas dan Validitas. Yogyakarta: Pustaka Belajar. 
Bartkus, K. R., Nemelka, B., Nemelka, M., \& Gardner, P. 2012. Clarifying The Meaning Of Extracurricular Activity: A Literature Review Of Definitions. American Journal of Business Education, 5(6), 693-704. Retrieved September 27, 2017, from www.cluteinstitute.com

Bierman Alex, Fazio Elena M, \& Milkie Melissa A. 2006. A Multifaceted Approach to the Mental Health Advantage of the Married: Assessing How Explanations Vary by Outcome Measure and Unmarried Group. Journal of Family Issues, 27, 554-582.

Christie, H., Tett, L., Cree, V. E., Hounsell, J., \& McCune, V. 2008. 'A real rollercoaster of confidence and emotions: learning to be a university student. Studies In Higher Education, 33(5), 567-581.

Eccles, J. S., \& Gootman, J. A. 2002. Community Programs to Promote Youth Development. Washinngton DC: National Academy Press.

Eddington, N., \& Shuman, R. 2005. Subjective Well-Being (Happiness). Continuing Psychology Education.

Foubert, J. D., \& Grainger, L. U. 2006. Effects of Involvement in Clubs and Organizations on the Psychosocial Development of First-Year and Senior College Students. NASPA Journal, 43(1), 166-182.

Gardner, M., Rot, J., \& Gunn, J. B. 2008. Adolescents's participation in organized activities and developmental success 2 and 8 years after high school: Do Sponshorship, duration, and intensity matter? Developmental Psychology, 44(3), 814-830.

Guzmanrocha, M. D., Mcleod, D. L., \& Bohnert, A. M. 2017. Dimension of Organized Activity Involvemnet Among Latino Youth: Impact On Well-Being. Journal of Adolescence, 60, 130-139.

Hansen, D. M., Larson, R. W., \& Dworkin, J. B. (2003). What adolescents learn in organized youth activities: A survey of selfreported developmental experiences. Journal of Research on Adolescence, 13, 25-55.

Katz, M. H. 2011. Multivariable analysis: a practical guide for clinicians and public health researchers. Cambridge university press.

Keyes, C. L., Shmotkin, D., \& Ryff, C. D. 2002. Optimizing well-being: the empirical encounter of two traditions. Journal of Personality and Social Psychology, 82(6), 1007-1022.

Larson, R. W., \& Varma, S. 1999. How children and adolescents spend time across the world: Work, play, and developmental opportunities. Psychological Bulletin, 125, 701736.

Mahoney, J. L., Larson, R. W., \& Eccles, J. S. 2005. Organized Activities as Contexts of Development: Extracurricular Activities, AfterSchool and Community Programs. Mahwah, 65-83.

Oosterhoff, B., Kaplow, J. B., Wray-Lake, L., \& Gallagher, K. 2017. Activityspecific Pathways Among Duration of Organized Activity Involvement, Social Support, and Adolescent Well-Being: Findings 
from A Nationally Representative Sample. Journal of Adolescence, 60, 83-93.

Ryan, R. M., \& Deci, E. L. 2001. On happiness and human potentials: a review of research on hedonic and eudaimonic well-being. Annual Review of Psychology, 52, 141166.

doi:https://doi.org/10.1146/annure v.psych.52.1.141

Ryff, C. D. 1989. Happiness Is Everything, or Is It? Explorations on the Meaning of Psychological Well-Being. Journal of Personality and Social Psychology, 57(6), 1069-1081.

Sihombing, A. F. 2017. Hubungan antara Dukungan Keluarga dengan Psychological Well-Being Pada Penderita Diabetes Mellitus Tipe 2. Skripsi. Universitas Surabaya.

Sugiyono. 2014. Metode penelitian kombinasi (mixed methods). Bandung: Alfabeta. 